\title{
Structures of coatings obtained in a ZnAl23Mg3Si0.4 bath by the batch hot dip method
}

\author{
H. Kania, A. Skupińska* \\ Silesian University of Technology, Institute of Materials Science, Krasińskiego 8, 40-019 Katowice, Poland
}

Received 27 April 2017, received in revised form 11 July 2017, accepted 13 July 2017

\begin{abstract}
The paper presents the results of the tests on ZnAl23Mg3Si0.4 coatings obtained by use of the batch hot dip method. The growth kinetics of coatings obtained at the temperature of $520^{\circ} \mathrm{C}$ on low-silicon steel has been defined. The structure has been developed, the chemical composition of structural components of the coatings and their phase composition have been established. It has been determined that coatings obtained in a ZnAl23Mg3Si0.4 bath are continuous and their average thickness ranges from 35.8 to $45.5 \mu \mathrm{m}$. The obtained coatings are composed of a diffusion layer of phase $\mathrm{FeAl}_{3}$ which contains $\mathrm{Zn}$ and $\mathrm{Si}$ and of an internal layer which contains solutions of $\mathrm{Al}$ and $\mathrm{Zn}$ as well as phases $\mathrm{MgZn}_{2}$ and $\mathrm{Mg}_{2} \mathrm{Si}$.
\end{abstract}

K e y w or d s: hot dip galvanizing, ZnAlMg coatings, galvanizing bath, corrosion resistance

\section{Introduction}

Zinc-aluminum coatings show better corrosion protection and the possibility of obtaining thinner coatings comparing to traditional zinc coatings. Aluminum protects both surface of the bath and the coating by creating passive layer $[1,2]$. What is more, it may be beneficial to obtain coatings from alloys containing a large amount of aluminum due to its higher volume than zinc and filling the same bath with a lower mass of the alloy. Another element added to zinc coatings that increases corrosion resistance is $\mathrm{Mg}[3-5]$ which also lowers the melting point of high-aluminum Zn$\mathrm{Al}$ alloys [6]. There are many zinc-aluminum alloys on the market [7-9], but they are dedicated to continuous galvanizing where the special treatment is applied. For batch hot dip method it is more difficult to obtain a coating with proper structure. Al reacts with Fe and fluxes making the process less effective. Additionally, zinc baths with high $\mathrm{Al}$ content require longer immersion times. Technological issues can be solved by double dipping, first in Zn bath and then in Zn-Al, which was proven by Tanaka [4] and in author's previous publications [10].

$\mathrm{A}$ wide range of $\mathrm{Al}$ content has been researched for galvanizing, from several to even $55 \%$ of $\mathrm{Al}$, al- though coatings obtained in baths with high $\mathrm{Al}$ content are characterized by an excessive thickness. Previous tests on $31 \% \mathrm{Al}$ zinc coatings showed that an addition of $\mathrm{Mg}$ does not significantly reduce the steel reactivity $[11,12]$, but it enhances corrosion resistance $[13]$.

The presence of $\mathrm{Si}$ in a bath ZnAl55 allows obtaining coatings of the right thickness and favorable structure $[14,15]$. Zn-Al alloys with a eutectoid composition $(23 \% \mathrm{Al})$ show the better ductility. It seems, then, that a favorable $\mathrm{Zn}-\mathrm{Al}$ bath composition would be a eutectoid composition with the addition of $\mathrm{Mg}$ and $\mathrm{Si}$, which ensures the right structure and thickness of the coating as well as its high corrosion resistance.

\section{Scope and methods of investigation}

The research aimed to define the structure and growth kinetics of coatings obtained in a $\mathrm{ZnAl} 23 \mathrm{Mg} 3$ Si0.4 bath. The alloy used in the test was prepared of pure elements ( $\mathrm{Zn}, \mathrm{Al}, \mathrm{Mg}, \mathrm{Si}$ ) and the industrial alloys Al-25\% Mg and AK11 silumin. Solidification point was established by the thermal analysis with ATD-CRYSTALDIGRAPH device. The recorded tempera-

*Corresponding author: e-mail address: anna.skupinska@polsl.pl 
Table 1. The chemical composition of steel (wt.\%)

\begin{tabular}{ccccccccccc}
\hline $\mathrm{C}$ & $\mathrm{Si}$ & $\mathrm{Mn}$ & $\mathrm{P}$ & $\mathrm{S}$ & $\mathrm{Cr}$ & $\mathrm{Ni}$ & $\mathrm{Mo}$ & $\mathrm{Al}$ & $\mathrm{Co}$ & Fe and other \\
\hline 0.075 & 0.013 & 0.571 & 0.0220 & 0.0159 & 0.019 & 0.019 & 0.006 & 0.0528 & 0.0022 & Remainder \\
\hline
\end{tabular}

ture at which solidification began was $495.4^{\circ} \mathrm{C}$. The temperature of the $\mathrm{ZnAl} 23 \mathrm{Mg} 3 \mathrm{Si} 0.4$ bath was set to $520^{\circ} \mathrm{C}$

The coatings were produced on low-silicon steel, which allowed to limit the influence of silicon content in the steel upon coating growth. The chemical composition of the steel is presented in Table 1.

The coatings were produced by double immersion. First, all the samples were immersed in pure zinc bath at the temperature of $450^{\circ} \mathrm{C}$ and the time of immersion of $30 \mathrm{~s}$. Immediately after taking samples out of a zinc bath, they were immersed in liquid ZnAl23Mg3Si0.4 alloy for 30, 60, 120 and 240 s. After the process, pieces were cooled in the air.

To establish the structure of thus produced coatings, metallographic tests were performed on a light microscope. Coating thicknesses were determined by using Elcometer 355 - an electromagnetic inductionbased gauge.

The chemical composition of coatings was established by the EDX analysis. The tests were performed on a Hitachi, type S-4200 scanning electron microscope with a microprobe analyzer and using the Voyager 3100 software by Noram Instruments. The applied accelerating voltage was $15 \mathrm{kV}$.

X-ray phase analysis was performed on a JEOL JDX-7S diffractometer, using an X-ray tube with a copper anode $\left(\lambda_{\mathrm{CuK} \alpha}=1.54178 \AA\right)$, powered by the current of $20 \mathrm{~mA}$ intensity and voltage of $40 \mathrm{kV}$ and a graphite monochromator. The records were taken by a stepwise method with the step of $0.05^{\circ}$ and the time of calculation being 3 seconds in the range from $10^{\circ}$ to $90^{\circ} 2 \theta$. Phase identification was performed by use of the ICDD PDF-4+ database. Diffractometry was carried out on the surface of diagonally polished samples with the coating in such a way that allowed to develop the phase composition of the whole section of the coating.

\section{Results and discussion}

\subsection{Growth kinetics}

The relationship between the average total thickness of coatings obtained in a $\mathrm{ZnAl} 23 \mathrm{Mg} 3 \mathrm{SiO} .4$ bath at the temperature of $520^{\circ} \mathrm{C}$ and the time of immersion is presented in Fig. 1. The thickness of coatings varies from 35.8 to $45.5 \mu \mathrm{m}$ as the time of immersion changed from 30 to $240 \mathrm{~s}$. The increase in the coating thickness along with growing time of immersion

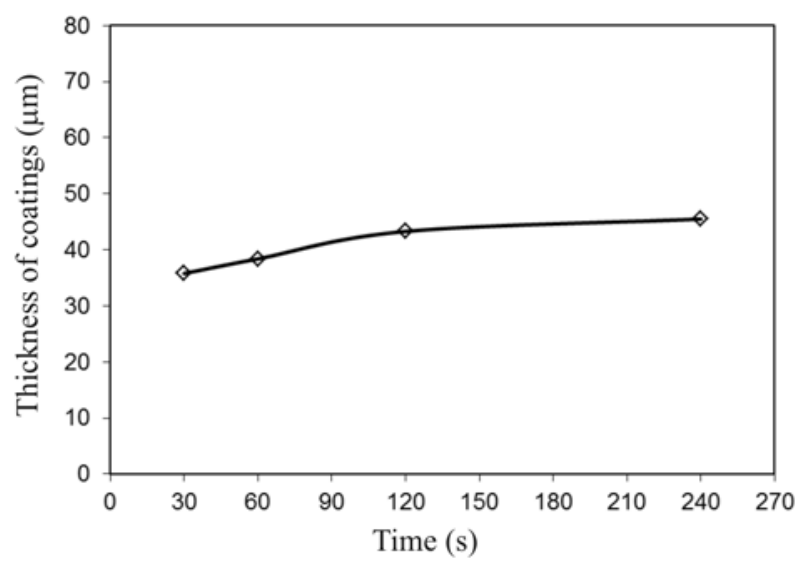

Fig. 1. Growth kinetics of coatings obtained in a $\mathrm{ZnAl} 23$ Mg3Si0.4 bath.

becomes slower, and the course of the growth curve becomes more parabolic.

\subsection{Cross section microstructure}

The structure of coatings obtained in a ZnAl23Mg3 Si0.4 bath is presented in Fig. 2. The coatings show good adhesion to the substrate, and there are no discontinuities or porosity. The coating is composed of an outer layer and a diffusion layer, whose thickness does not change much as the time of immersion prolongs. Morphology of the phases is not characteristic for Fe-Zn intermetallic phases. We may thus say, that the initially produced zinc coating was utterly reconstructed.

\subsection{EDS and SEM results}

The microstructure of the coating obtained on lowsilicon steel in a $\mathrm{Zn}-23 \mathrm{Al} 3 \mathrm{Mg} 0.4 \mathrm{Si}$ bath and the results of EDX analysis of selected micro-areas are presented in Fig. 3. The contents of analyzed elements are presented, in percentage terms, in Table 2. In the outer layer, areas rich in $\mathrm{Al}$ and $\mathrm{Zn}$ are visible. However, they differ significantly in the contents of component elements. They also form a characteristic shape. These are the darker areas, oval in shape and of a uniform structure (point 2). They are surrounded by a layer which is brighter and which has a more heterogeneous structure (point 3). In the darker zone of a uniform structure, Al prevails (point 2), while in the brighter, outer zone (point 3) $\mathrm{Zn}$ is predominant. A similar chemical composition, rich in $\mathrm{Zn}$, is that of the struc- 

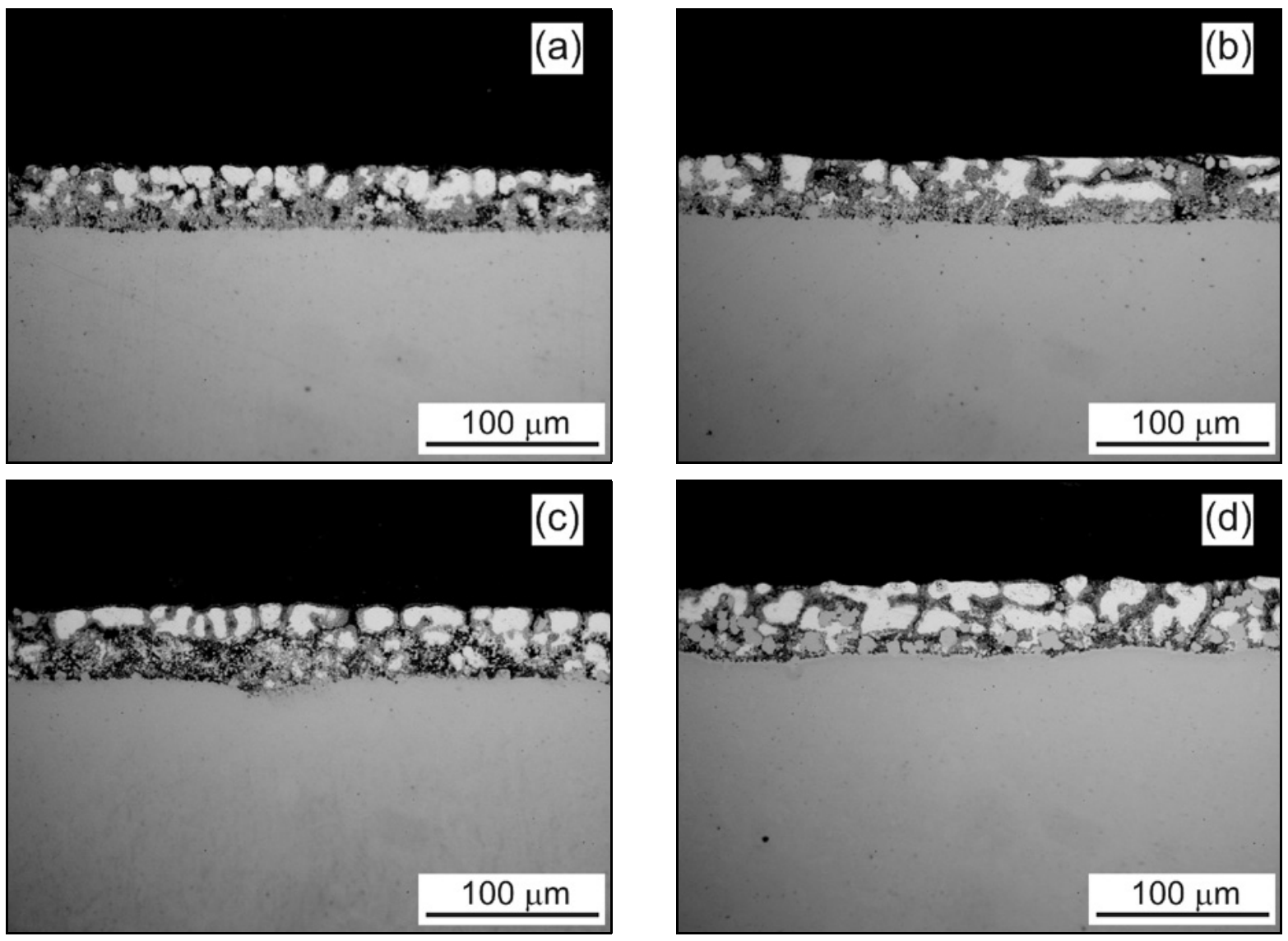

Fig. 2. The structure of coatings obtained in a ZnAl23Mg3Si0.4 bath - time of immersion: (a) $30 \mathrm{~s}$, (b) $60 \mathrm{~s}$, (c) $120 \mathrm{~s}$, and (d) $240 \mathrm{~s}$.

Table 2. The chemical composition of selected micro-areas of the coating obtained in a ZnAl23Mg3Si0.4 bath (points of analysis according to Fig. 3)

\begin{tabular}{|c|c|c|c|c|c|c|c|c|}
\hline \multirow{3}{*}{ Point of measurement } & \multicolumn{8}{|c|}{ Element contents } \\
\hline & \multicolumn{2}{|c|}{$\mathrm{Mg}-\mathrm{K}$} & \multicolumn{2}{|c|}{ Al-K } & \multicolumn{2}{|c|}{$\mathrm{Si}-\mathrm{K}$} & \multicolumn{2}{|c|}{$\mathrm{Zn}-\mathrm{K}$} \\
\hline & $($ wt.\%) & (at.\%) & (wt.\%) & (at.\%) & (wt.\%) & (at.\%) & $($ wt.\%) & (at.\%) \\
\hline point 1 & 57.1 & 62.5 & - & - & 37,1 & 35.1 & 5.7 & 2.3 \\
\hline point 2 & - & - & 57.0 & 76.3 & - & - & 43.0 & 23.7 \\
\hline point 3 & - & - & 42.6 & 64.3 & - & - & 57.4 & 35.7 \\
\hline point 4 & 13.5 & 28.9 & 2.1 & 4.0 & - & - & 84.4 & 67.0 \\
\hline point 5 & & & 34.6 & 56.1 & - & - & 65.4 & 43.9 \\
\hline
\end{tabular}

tural element defined in point 5 . Due to different morphology, it is hard to determine, whether it is a separate structural element of the coating or an element of the structure which surrounds areas rich in $\mathrm{Al}$. Al contents in phases containing $\mathrm{Al}$ and $\mathrm{Zn}$ are much higher than $\mathrm{Al}$ content in the bath. Moreover, we may distinguish the presence of components rich in $\mathrm{Mg}$ and $\mathrm{Zn}$ (point 4) and rich in $\mathrm{Mg}$ and $\mathrm{Si}$ (point 1) in the outer layer.

We can observe the presence of dendritic crystals in the outer layer. The microstructure of that zone of the coating is presented in Fig. 4. EDX and the chemical composition defined for the dendrite area (point 8) point to the presence of a solution of $\mathrm{Al}$ in $\mathrm{Zn}$ ( $\mathrm{Ta}$ ble 3 ). We can also see a separate phase containing $\mathrm{Mg}$ along the borders of dendrites of the solid solution of $\mathrm{Al}$ in $\mathrm{Zn}$ (point 7 ). In that zone of the coating, micro-analysis of the chemical composition indicated that the dark, oval areas of a uniform structure (point 7), as well as the layer of a heterogeneous struc- 

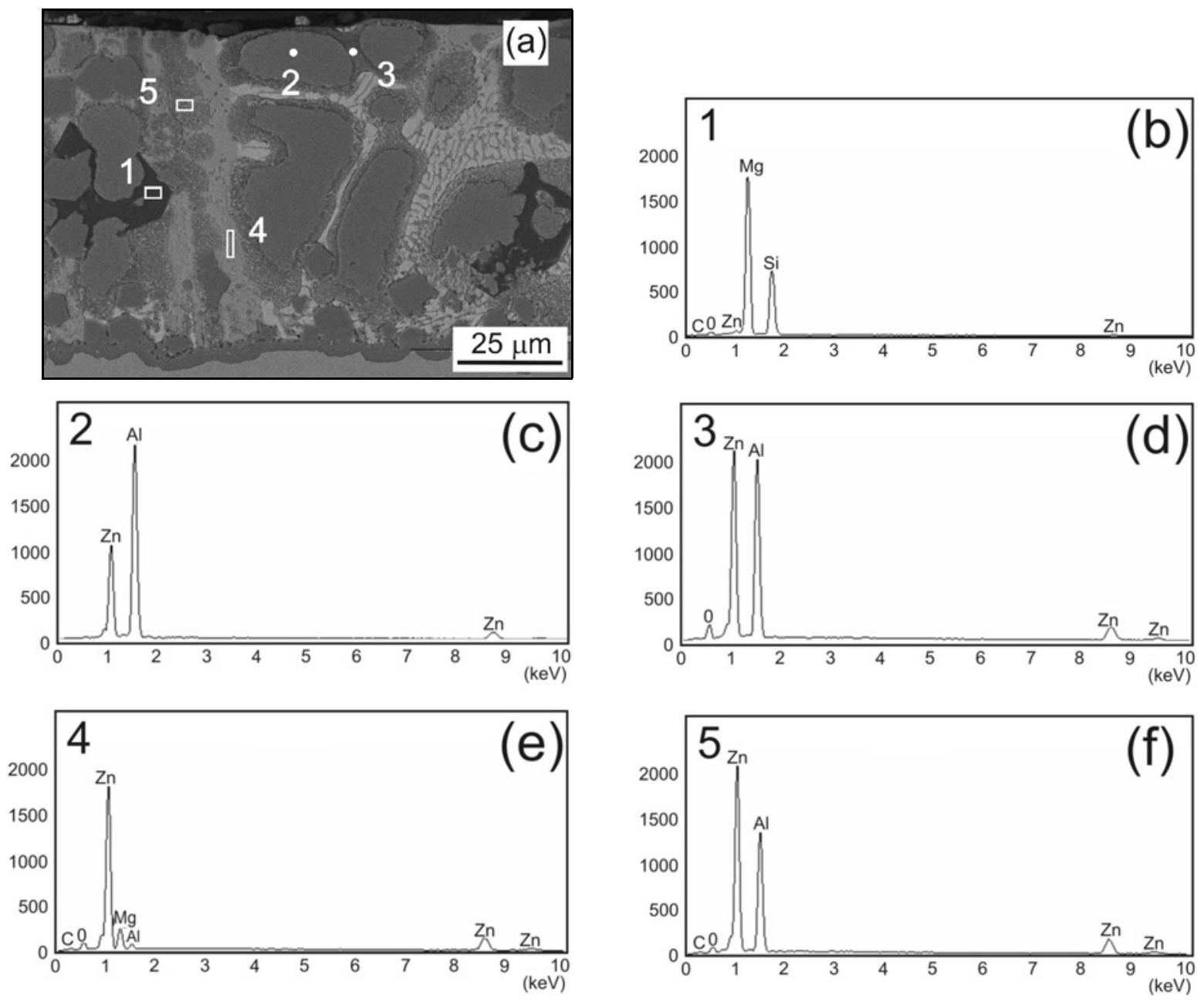

Fig. 3. The microstructure of the coating obtained in a ZnAl23Mg3Si0.4 bath (a), and the EDX analysis of selected micro-areas of the coating $(\mathrm{b}-\mathrm{f})$.

Table 3. The chemical composition of selected micro-areas in the outer layer zone of the coating obtained in a ZnAl23Mg3Si0.4 bath (points of analysis according to Fig. 4)

\begin{tabular}{|c|c|c|c|c|c|c|}
\hline \multirow{3}{*}{ Point of measurement } & \multicolumn{6}{|c|}{ Element contents } \\
\hline & \multicolumn{2}{|c|}{$\mathrm{Mg}-\mathrm{K}$} & \multicolumn{2}{|c|}{ Al-K } & \multicolumn{2}{|c|}{$\mathrm{Zn}-\mathrm{K}$} \\
\hline & $(\mathrm{wt} . \%)$ & (at.\%) & (wt.\%) & (at.\%) & (wt.\%) & (at.\%) \\
\hline point 6 & 0.7 & 1.2 & 42,0 & 63.2 & 57.3 & 35.6 \\
\hline point 7 & 0.4 & 0.6 & 58.0 & 76.7 & 41.6 & 22.7 \\
\hline point 8 & - & - & 1.4 & 3.3 & 98.6 & 96.7 \\
\hline point 9 & 2.2 & 5.6 & 1.2 & 2.8 & 96.6 & 91.5 \\
\hline
\end{tabular}

ture that surrounds them (point 6 ), may also contain small amounts of $\mathrm{Mg}$.

The microstructure of the coating directly at the steel substrate is presented in Fig. 5. The diffusion layer contains $48.9 \mathrm{wt} . \% \mathrm{Al}$ and $29.2 \mathrm{wt} . \% \mathrm{Fe}$ as well as $\mathrm{Zn}$ (point 12, Table 4). Based on the chemical composition, we may suspect that this is probably the Fe-Al intermetallic phase enriched with zinc. The presence of
6.6 wt.\% Si has also been observed in that layer. The structure of the diffusion layer is relatively compact with no precipitations so we can deduce that Si dissolves in the intermetallic phases that are formed on the substrate. The chemical composition of characteristic dark areas of a uniform structure (point 10) surrounded by a brighter, heterogeneous layer (point 11) is similar to those that occur on the coating's surface. 

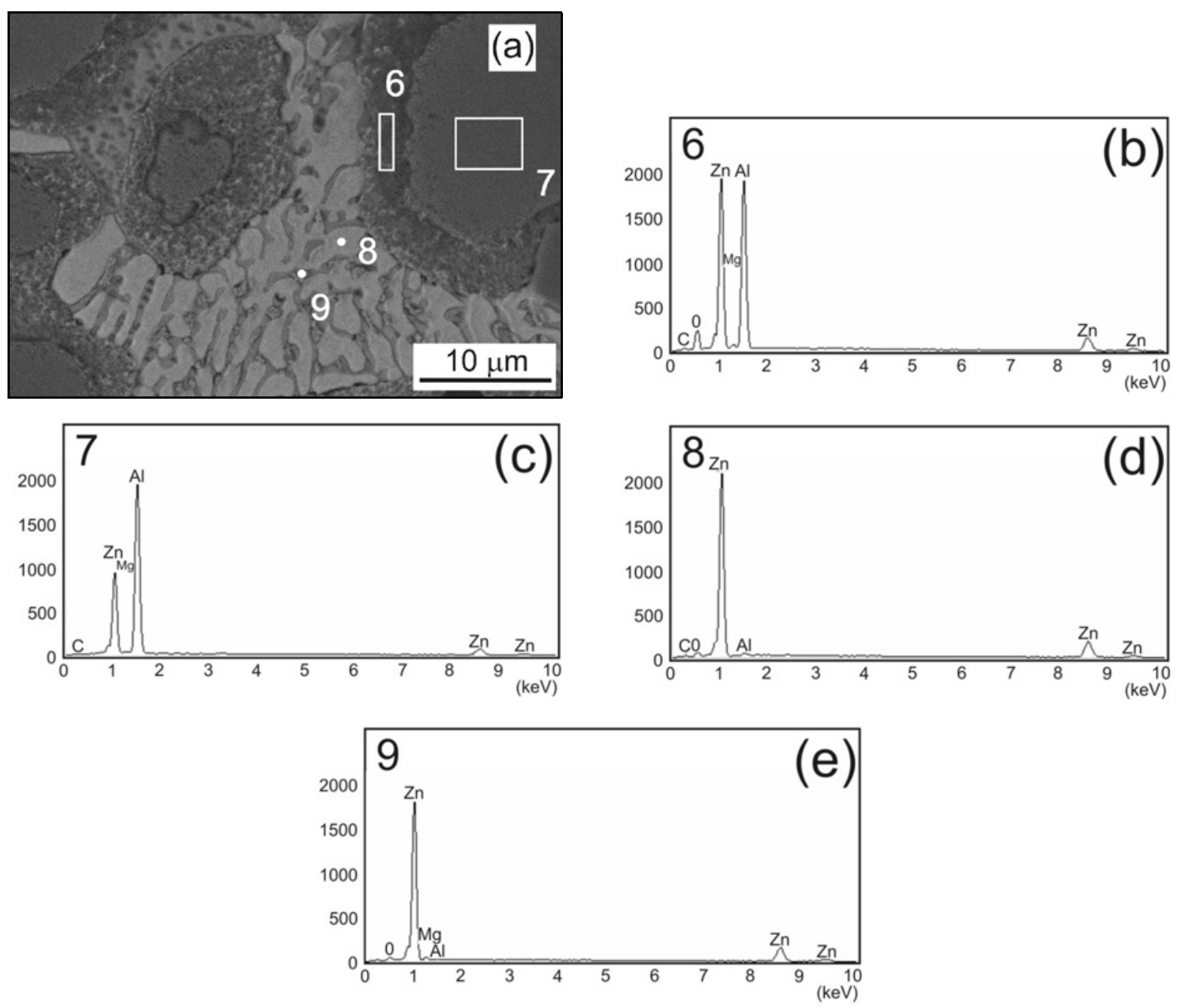

Fig. 4. The microstructure of the outer layer zone of the coating obtained in a ZnAl23Mg3Si0.4 bath (a), and the EDX of selected micro-areas (b-e).

Table 4. The chemical composition of selected micro-areas in the diffusion layer zone of the coating obtained in a ZnAl23Mg3Si0.4 bath (points of analysis according to Fig. 5)

\begin{tabular}{|c|c|c|c|c|c|c|c|c|}
\hline \multirow{3}{*}{ Point of measurement } & \multicolumn{8}{|c|}{ Element contents } \\
\hline & \multicolumn{2}{|c|}{ Al-K } & \multicolumn{2}{|c|}{ Si-K } & \multicolumn{2}{|c|}{$\mathrm{Fe}-\mathrm{K}$} & \multicolumn{2}{|c|}{$\mathrm{Zn}-\mathrm{K}$} \\
\hline & (wt.\%) & (at.\%) & (wt.\%) & (at.\%) & (wt.\%) & (at.\%) & (wt.\%) & (at.\%) \\
\hline point 10 & 61.2 & 79.3 & - & - & - & - & 38.8 & 20.7 \\
\hline point 11 & 36.7 & 58.3 & - & - & 1.4 & 1.1 & 62.0 & 40.6 \\
\hline point 12 & 48.9 & 64.7 & 6.6 & 8.4 & 29.2 & 18.6 & 15.3 & 8.3 \\
\hline
\end{tabular}

$\mathrm{No} \mathrm{Mg}$ has been observed in them. Distribution of elements in coatings is similar to results published by Tanaka et al. [16] with Mg accumulated in the outer layer, which may cause the better corrosion resistance.

\subsection{XRD results}

$\mathrm{XRD}$ of the surface of an oblique polished section of the coating obtained in a Zn-23Al3Mg0.4Si bath (Fig. 6) confirms the presence of $\mathrm{Al}$ and $\mathrm{Zn}$. Thus, the coating's structural elements, which have $\mathrm{Al}$ and $\mathrm{Zn}$ in their composition constitute solutions of those metals. The diffractogram also confirmed the presence of phase $\mathrm{FeAl}_{3}$ and $\mathrm{MgZn}_{2}$ although it did not confirm the presence of $\mathrm{Fe}_{2} \mathrm{Al}_{5}$ phase reported by Gao et al. [17]. Based on the chemical composition in micro- 

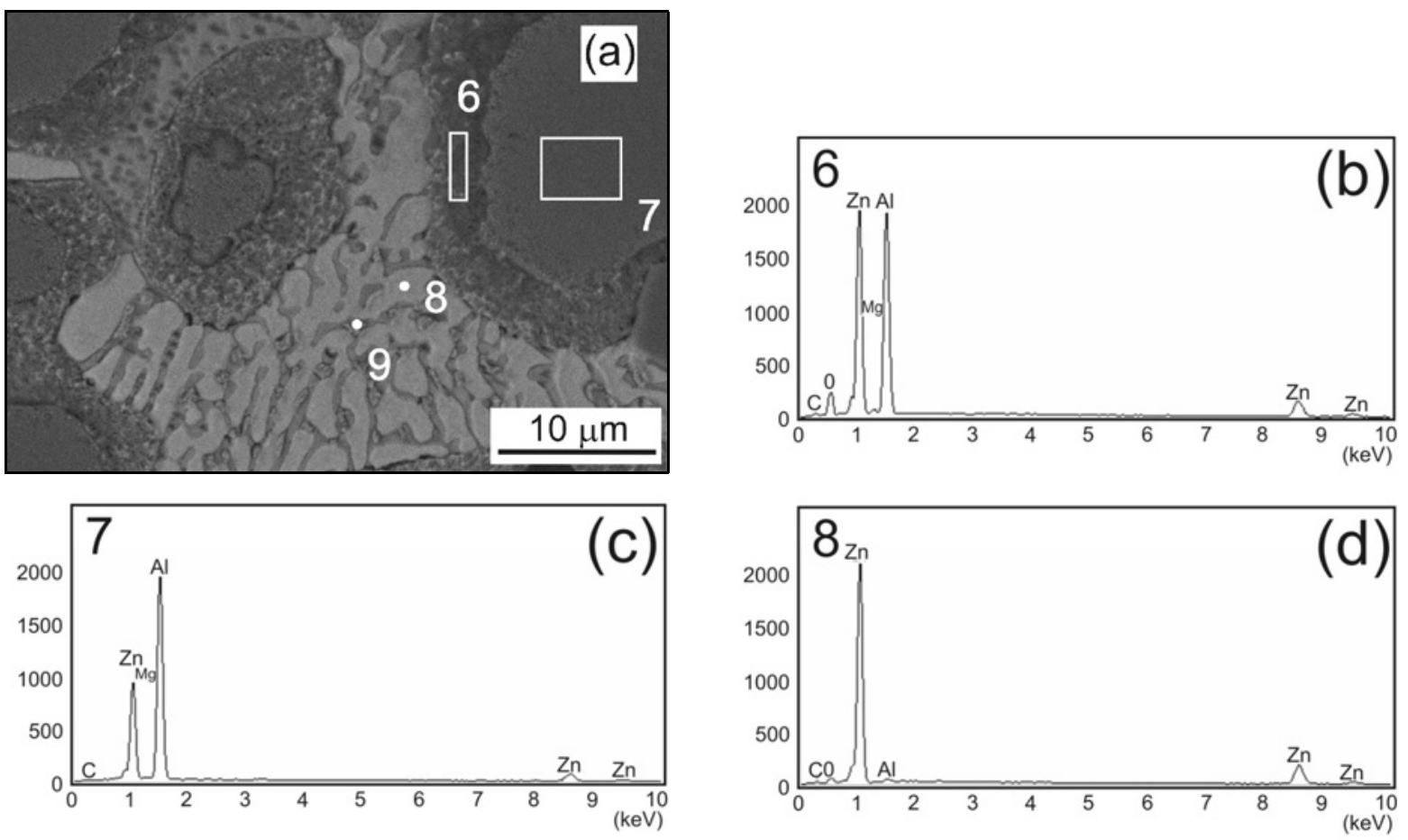

Fig. 5. The microstructure in the diffusion layer zone of the coating obtained in a ZnAl23Mg3Si0.4 bath (a), and the EDX analysis of selected micro-areas $(b-d)$.

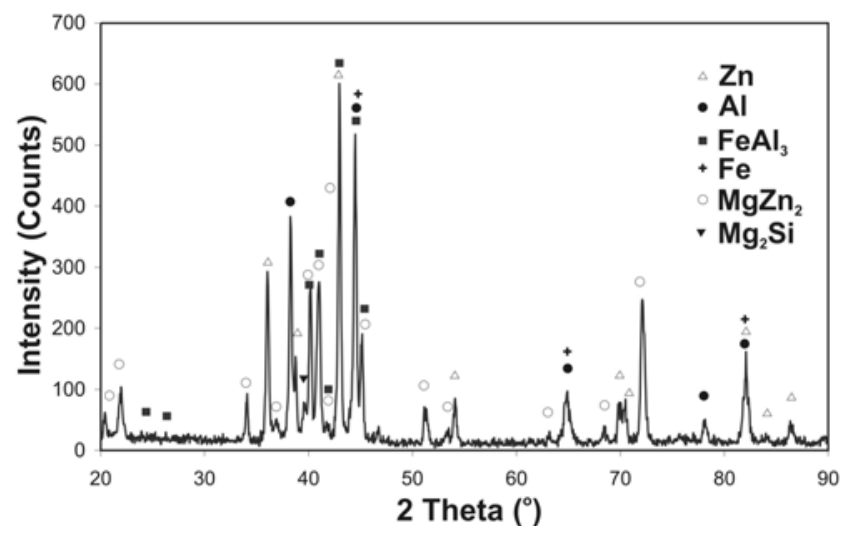

Fig. 6. Diffractograms of the surface of an oblique polished section of the coating obtained in a Zn23Al3Mg0.4Si bath.

areas, we may say that the phase of $\mathrm{FeAl}_{3}$ is a continuous layer that is formed on the substrate, and it contains a high concentration of $\mathrm{Fe}$ and $\mathrm{Al}$. The phase may dissolve significant amounts of $\mathrm{Zn}$. On the other hand, the phase of $\mathrm{MgZn}_{2}$ occurs in areas of high concentration of $\mathrm{Mg}$ and $\mathrm{Zn}$. The phase may form larger areas that spread along the whole section of the outer layer of the coating (Fig. 3, point 4). High concentration of $\mathrm{Mg}$ and $\mathrm{Zn}$ is also present in the phase which is separated at the border of dendrites of $\mathrm{Al}$ solution in $\mathrm{Zn}$ in the outer layer (Fig. 4, point 9). Due to the small size of these precipitates, the defined chemical compo- sition may differ from the real one. On the diffractogram, the characteristic spectrum of phase $\mathrm{Mg}_{2} \mathrm{Si}$ was identified. The diffractogram does not explicitly confirm the presence of phase $\mathrm{Mg}_{2} \mathrm{Si}$, as this phase's share in the coating is small, and there is a possibility that peaks of the characteristic spectrum of that phase are concealed by peaks of high intensity coming from other phases. In the structure of the coating obtained in a $\mathrm{Zn}-23 \mathrm{Sl} 3 \mathrm{Mg} 0.4 \mathrm{Si}$ bath, there are areas containing $\mathrm{Mg}, \mathrm{Si}$ and the small amounts of $\mathrm{Zn}$ (Fig. 3, point 1). So we should think that these are precipitates of phase $\mathrm{Mg}_{2} \mathrm{Si}$ which was also confirmed by Honda et al. [18] where the similar contents of $\mathrm{Mg}$ and $\mathrm{Si}$ have been tested.

\section{Conclusions}

Even though production of $\mathrm{Zn}-\mathrm{Al}$ using the batch hot dip method is technologically difficult, conducted tests showed that production of continuous coatings with correct structure is possible if the method of double immersion is used. The coatings obtained in a $\mathrm{ZnAl} 23 \mathrm{Mg} 3 \mathrm{Si} 0.4$ bath at the temperature of $520^{\circ} \mathrm{C}$ have the proper thickness. As the time of immersion changes from 30 to $240 \mathrm{~s}$, the coating thickness ranges from 35.8 to $45.5 \mu \mathrm{m}$. The growth kinetics curve is close to parabolic, which makes the control of the coating thickness easier.

Coatings obtained in a $\mathrm{ZnAl} 23 \mathrm{Mg} 3 \mathrm{Si} 0.4$ bath have 
a two-layered structure. The diffusion layer of a compact structure is formed directly on the substrate. Based on X-ray phase analysis and chemical composition tests of micro-areas, we may say that it is a phase of $\mathrm{FeAl}_{3}$ which contains $\mathrm{Zn}$ and $\mathrm{Si}$. The outer layer has a complex phase composition. We may distinguish areas of $\mathrm{Al}$ and $\mathrm{Zn}$ solutions with various component contents. Spaces between them are filled with the phase of $\mathrm{MgZn}_{2}$ and dendrites of $\mathrm{Al}$ solid solution in $\mathrm{Zn}$, with precipitates of phase $\mathrm{MgZn}_{2}$ located in spaces in-between the dendrites. Precipitates of phase $\mathrm{Mg}_{2} \mathrm{Si}$ are also present in the outer layer. No $\mathrm{Fe}-\mathrm{Zn}$ intermetallic phases of the initially formed zinc coating were observed in the coating structure.

\section{Acknowledgement}

This work was supported by the National Science Centre, Poland, Project No N N508 592939.

\section{References}

[1] Kania, H., Liberski, P.: IOP Conf. Series: Materials Science and Engineering, 35/012004, 2012. doi:10.1088/1757-899X/35/1/012004

[2] Kania, H., Liberski, P.: State Phenomena, 212, 2014, p. 115. doi:10.4028/www.scientific.net/SSP.212.115

[3] Saternus, M., Fornalczyk, A., Kania, H., Mendala, J.: Solid State Phenomena, 246, 2016, p. 99. doi:10.4028/www.scientific.net/SSP.246.99

[4] Tanaka, S., Honda, K., Takahashi, A., Morimoto, Y., Kurosaki, M., Shindo, H., Nishimura, K., Sugiyama, M.: In: Proceedings of GALVATECH'01. Dusseldorf, Verlag Stahleisen GmbH, 2001, p. 153. ISBN 3-514-00673-3.

[5] Tsujimura, T., Komatsu, A., Andoh, A.: In: Proceedings of GALVATECH'01. Dusseldorf, Verlag Stahleisen GmbH 2001, p. 145. ISBN 3-514-00673-3.
[6] Nowacki, K., Kania, H., Wieczorek, J., Smalcerz, A.: Solid State Phenomena, 246, 2016, p. 143. doi:10.4028/www.scientific.net/SSP.246.143

[7] Nishimura, K., Shindo, H., Kato, K., Morimoto, Y.: In: Proceedings of GALVATECH'98. Ed.: Masako, N. Tokyo, The Iron and Steel Institute of Japan 1998, p. 437.

[8] Tano, K., Higuchi, S.: Nippon Steel Technical Report, 25,1985, p. 29.

[9] Volt, M., Bleeker, R., Maalman, T., van Perlstein, E.: In: Proceedings of the Galvanized Steel Sheet Forum MagiZinc ${ }^{\text {TM }}$ : A New Generation of Hot-Dip Galvanized Products. Dusseldorf, ILZRO and IZA 2006, p. 13.

[10] Liberski, P., Kania H., Podolski, P.: Physicochemical Mechanics of Materials, 5, 2006, p. 673.

[11] Kania, H.: IOP Conf. Series: Materials Science and Engineering, 35, 2012, p. 012003. doi:10.1088/1757-899X/35/1/012003

[12] Kania, H.: Solid State Phenomena, 212, 2014, p. 101. doi:10.4028/www.scientific.net/SSP.212.101

[13] Kania, H., Bierońska, M.: Solid State Phenomena, 212, 2014, p. 167. doi:10.4028/www.scientific.net/SSP.212.167

[14] Mendala, J.: IOP Conf. Series: Materials Science and Engineering, 22, 2011, p. 012004. doi: $10.1088 / 1757-899 \mathrm{X} / 22 / 1 / 012004$

[15] Mendala, J.: IOP Conf. Series: Materials Science and Engineering, 22, 2011, p. 012005. doi:10.1088/1757-899X/22/1/012005

[16] Tanaka, J., Ono, K., Hayashi, S., Ohsasa, K., Narita, T.: ISIJ International, 42, 2002, p. 80. doi:10.2355/isijinternational.42.80

[17] Gao, L., Li, Z., Kuang, X., Yin, F., Ji, H.: Surface and Coatings Technology, 304, 2016, p. 306. doi:10.1016/j.surfcoat.2016.07.027

[18] Honda, K., Ushioda, K., Yamada, W.: ISIJ International, 51, 2011, p. 1895.

doi:10.2355/isijinternational.51.1895 